\title{
SÍNDROME DE MILLER FISHER, OFTALMOPLEJÍA INTERNA Y EXTERNA TRAS VACUNACIÓN ANTIGRIPAL
}

\section{MILLER FISHER SYNDROME, INTERNAL AND EXTERNAL OPHTHALMOPLEGIA AFTER FLU VACCINATION}

\author{
BLANCO-MARCHITE CI ${ }^{1}$, BUZNEGO-SUÁREZ L ${ }^{1}$, FAGÚNDEZ-VARGAS MA ${ }^{2}$, \\ MÉNDEZ-LLATAS $\mathrm{M}^{1}$, POZO-MARTOS $\mathrm{P}^{1}$
}

\section{RESUMEN}

Caso clínico: El síndrome de Miller Fisher (SMF) es la variante más frecuente del síndrome de Guillain Barré. Se caracteriza por la tríada clásica de oftalmoplejía, ataxia y arreflexia.

Se expone el caso de un paciente que presenta esta clínica a los 5 días de recibir la vacuna antigripal.

Discusión: El síndrome de Miller Fisher se encuentra con poca frecuencia en la práctica clínica. Están descritos cuadros asociados a infecciones respiratorias y digestivas, pero no ha sido descrito secundario a la vacuna de la gripe.

Palabras claves: Anticuerpos Anti-GQ1b, oftalmoplejía interna, oftalmoplejía externa, ataxia, arreflexia, vacunación antigripal, síndrome de Miller Fisher.

\section{INTRODUCCIÓN}

El síndrome de Miller Fisher (SMF) es una poliradiculopatía monofásica . Se caracteriza por la tríada clásica de oftalmoplejía, ataxia y arreflexia. Generalmente se asocia a infecciones respiratorias o digestivas.

Se presenta el caso de un paciente con SMF cuyo único antecedente era haber sido vacunado contra la gripe cinco días antes.

\begin{abstract}
Case report: Miller Fisher Syndrome (MFS) is the most frequent variant of the Guillain-Barré Syndrome. It is characterised by the classic triad of ophthalmoplegia, ataxia and areflexia. We present a case of a patient who developed these clinical findings 5 days after flu vaccination.
\end{abstract}

Discussion: Miller Fisher Syndrome is an unusual condition seen in ophthalmologic clinical practice. Although respiratory and digestive infections have been reported as antecedent infectious agents in MFS, it has not previously been described in relation to the flu vaccine (Arch Soc Esp Oftalmol 2008; 83: 433-436).

Key words: Anti-GQ1b antibody, internal opthalmoplegia, external ophthalmoplegia, ataxia, areflexia, antiflu vaccine, Miller Fisher syndrome.

\footnotetext{
Recibido: 7/3/07. Aceptado: 21/5/08.

Servicio de Oftalmología. Complejo Hospitalario Universitario de Albacete SESCAM. Albacete. España.

1 Licenciado en Medicina.

2 Doctor en Medicina.

Correspondencia:

Cristina Isabel Blanco Marchite

C/. Alcalde Martínez de la Ossa, 1-5E

02001 Albacete

España

E-mail: cblancomar@yahoo.es
} 
La agudeza visual era 0,7 en ambos ojos (AO), y presentaba ambas pupilas dilatadas y arrefléxicas, sin que hubiera contacto previo con midriáticos (fig. 1). Presentaba una limitación en la abducción de AO, mayor en ojo izquierdo (OI) (fig. 2), en la supraducción de AO (fig. 3), y dificultad para el resto de los movimientos oculares, refiriendo diplopia horizontal. El resto de la exploración oftalmológica era normal.

Ante la sospecha diagnóstica de un síndrome de Miller Fisher se remite al servicio de Neurología, que detecta una marcha atáxica, hiporreflexia, y descarta debilidad de miembros, decidiendo el ingreso para seguimiento y estudio completo. Los resultados de los análisis de sangre y de la tomografía axial computarizada (TAC) realizada de urgencias fueron normales.

A las 24 horas del ingreso apareció una dificultad respiratoria que precisó oxígeno y fisioterapia, y en las semanas siguientes fue desarrollando nuevos síntomas neurológicos: parálisis facial, disfonía y disfagia.

Durante el ingreso se realizó una punción lumbar en la que se detectó una disociación albúmino-citológica, y una resonancia magnética nuclear (RMN) que descartó definitivamente lesión ocupante de espacio o desmielinización. El estudio electromiográfico no aportó información adicional.

El estudio inmunológico fue positivo para el anticuerpo anti GQ-1b, confirmando definitivamente el diagnóstico inicial.

El paciente mejoró de sus síntomas a las dos semanas del ingreso, habiendo recibido dos ciclos de inmunoglobulinas. La evolución clínica fue lenta y polisintomática, persistiendo la diplopía con limitación de la abducción bilateral de forma prolongada.

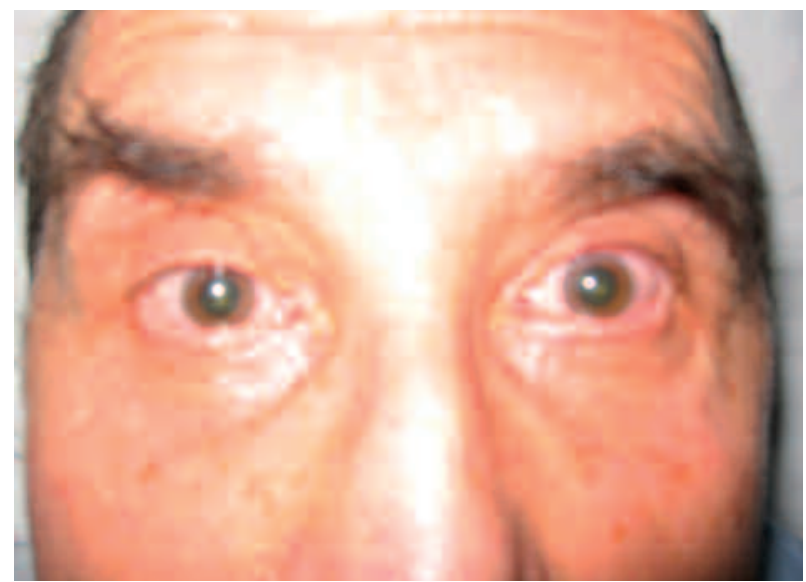

Fig. 1: Oftalmoplejía interna en la exploración inicial.

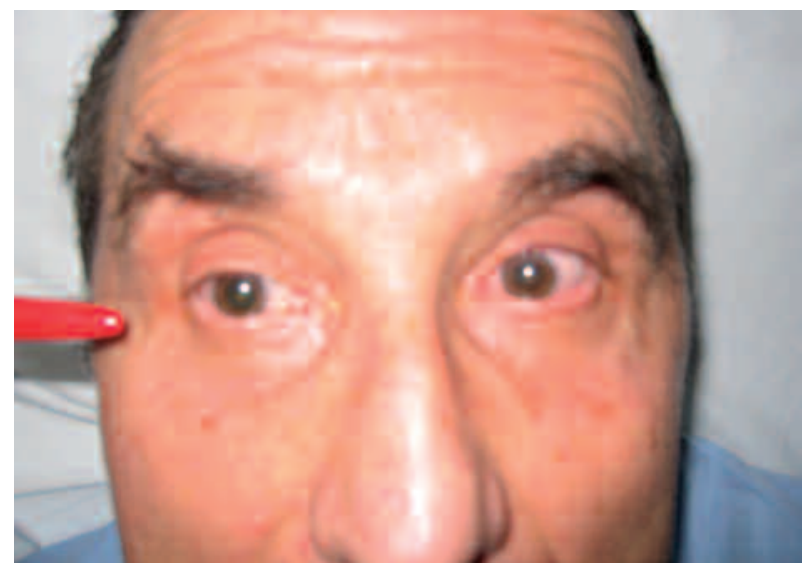

Fig. 2: Motilidad ocular extrínseca: limitación en la abducción del $O D$.

\section{DISCUSIÓN}

El síndrome de Miller Fisher es un cuadro neurológico periférico que se asocia en la mayoría de los casos a un proceso infeccioso (1) sobre todo respiratorio o digestivo. El tiempo medio de aparición de los síntomas neurológicos tras la infección es de 12 semanas, y el diagnóstico se basa en demostrar la seroconversión. Rara vez se asocia al proceso en su fase aguda (2). Nuestro caso no se asoció a infección crónica o aguda, pero sí a la vacuna antigripal.

Se considera que se desencadena por un proceso autoinmune. La existencia en suero de títulos elevados de anticuerpos antigangliósidos antiGQ1b, analizados mediante ELISA (3), es específica del SMF, aunque estudios posteriores los han asociado también al síndrome de Guillain-Barré con oftalmople-

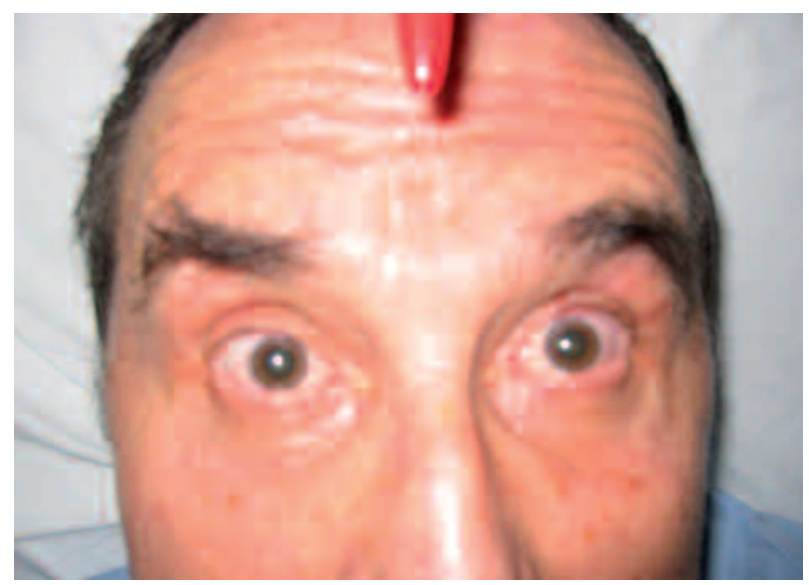

Fig. 3: En supraducción se observa dificultad para elevar ambos ojos. 
jia, a la troncoencefalitis de Bickerstaff (4) y a la oftalmoparesia aguda sin ataxia.

El nervio óptico y los nervios oculomotores contienen una alta cantidad de gangliósidos GQ1b. Algunos agentes infecciosos comparten epítopos homónimos (1) con algunos gangliósidos de superficie de los nervios periféricos, desencadenando la producción de anticuerpos frente a éstos y una reacción cruzada con los tejidos nerviosos. El anticuerpo se une a las cadenas de las regiones paranodales de la porción infranuclear de los nervios oculomotor, troclear y abducens y más débilmente al núcleo cerebral, bloqueando al nervio motor, y sería responsable de la ataxia y la oftalmoplejía.

Quizás la vacuna antigripal comparte también estos epítopos, desencadenando el cuadro de nuestro paciente.

La tríada típica de este síndrome la constituyen la oftalmoplejía, la ataxia y la arreflexia. Habitualmente se inicia con una limitación en la abducción (1), y hay casos en los que no se produce una oftalmoplejía completa. Cuando nuestro paciente acude a urgencias presentaba una parálisis en la abducción, con limitación del resto de movimientos oculares, y en horas desarrolló una parálisis completa de todos los músculos extraoculares, sin ptosis. Desde el inicio presentó ataxia e hiporreflexia.

Otros síntomas que pueden desarrollar son disfagia, disfonía, parálisis facial o insuficiencia respiratoria. La dificultad respiratoria es más frecuente en pacientes mayores, como el de este caso, y suelen precisar soporte respiratorio mecánico, teniendo peor pronóstico y mayor índice de recaídas. Ante la presencia de insuficiencia respiratoria debe descartarse un síndrome de Guillain-Barré con oftalmoplejía, difícil por la inespecificidad de las pruebas y por tratarse de un diagnóstico sobre todo clínico.

Dentro de la oftalmoplejía, la interna es la menos frecuente (4). Ante este signo se debe hacer diagnóstico diferencial con una lesión dorsal pontomesencefálica (ictus, encefalitis, lesión expansiva), la mayoría de las veces descartable por la clínica y las pruebas de imagen; y con el botulismo, en el que se produce también una leve midriasis arrefléxica y disfagia, y en el que la historia clínica y signos acompañantes sugieren el diagnóstico. En ambos casos la aparición de anticuerpos antigangliósidos permitiría descartar uno y otro cuadro.

Para explicar el mecanismo de la oftalmoplejía interna, Radziwill (4) supone que los anticuerpos anti GQ-1b podrían unirse al ganglio ciliar, igual que se unen a las regiones paranodales de los nervios responsables de la motilidad ocular extrínseca, produciendo la denervación del esfínter pupilar (5). Distintos autores se han servido del test de hipersensibilidad pupilar, que sugiere que existe una sensibilidad aumentada del músculo esfínter pupilar a la instilación de pilocarpina al 0,125\% (4). Este es un indicador útil de la presencia de disfunción parasimpática postganglionar; por ello proponen que la afectación es principalmente periférica.

La ausencia de alteración en la RMN y los hallazgos electroneurográficos compatibles con la polirradiculopatía desmielinizante apoyan la localización periférica lesional de esta sintomatología.

En conclusión, presentamos un caso poco frecuente como es el SMF, con afectación de la motilidad ocular intrínseca, que ocurre sólo en el $37 \%$ de los casos, en un paciente sin historia previa de infección. El único antecedente relatado fue la vacuna contra la gripe 5 días antes. No hemos encontrado en la literatura ningún caso en que se asocie este síndrome con vacunación previa, a diferencia con el síndrome de Guillain-Barré.

El SMF se describe como un cuadro benigno, y es tratado con frecuencia con inmunoglobulinas, que aunque de eficacia discutida (algunos autores presentan casos que no precisaron tratamiento) (2) parece ser que aceleran la recuperación. Sin embargo, no puede considerarse un cuadro banal; en nuestro caso el paciente precisó soporte respiratorio, y la evolución clínica fue lenta y polisintomática, persistiendo la diplopía con limitación de la abducción bilateral de forma prolongada.

\section{BIBLIOGRAFÍA}

1. Yuki N, Odaka M, Hirata K. Acute ophthalmoparesis (without ataxia) associated with anti-GQ1b IgG antibody: clinical features. Ophthalmology 2001; 108: 196-200.

2. Bernal Sánchez-Arjona M, Franco-Macías E, VillalobosChaves F. Síndrome de Miller Fisher que complica una neumonía aguda por Micoplasma pneumoniae. Rev Neurol 2003; 36: 235-237.

3. Kaida K, Kanzaki M, Morita D, Kamakura K, Motoyoshi $K$, Hirakawa $M$, et al. Anti-ganglioside complex antibodies in Miller Fisher syndrome. J Neurol Neurosurg Psychiatry 2006; 77: 1043-1046.

4. Sugita A, Yanagisawa T, Kamo T, Takahashi Y,Yuki N. Internal ophthalmoplegia with anti-GQ1b IgG antibody. $J$ Neurol 2002; 249: 1475-1476.

5. Chan YC, Wilder-Smith E, Chee MW. Acute ophthalmoplegia with pupillary areflexia associated with anti-GQ1b antibody. J Clin Neurosci 2004; 11: 658-660. 